NBER WORKING PAPER SERIES

\title{
TIME IN PURGATORY: \\ DETERMINANTS OF THE GRANT LAG \\ FOR U.S. PA TENT APPLICATIONS
}

\author{
David Popp \\ Ted Juhl \\ Daniel K.N. Johnson \\ Working Paper 9518 \\ http://www.nber.org/papers/w9518 \\ NATIONAL BUREAU OF ECONOMIC RESEARCH \\ 1050 Massachusetts Avenue \\ Cambridge, MA 02138 \\ February 2003
}

We thank the patent examiners and members of the United States Patent and Trademark Office Staff who made the interviews included in this work possible. Special thanks to Catherine Gerard and Bo Bounkong for their efforts in getting the interviews started, and to Willow Jacobson for sharing her insights on the Patent Office. The views expressed herein are those of the author and not necessarily those of the National Bureau of Economic Research.

(C2003 by David Popp, Ted Juhl, and David K. N. Johnson. All rights reserved. Short sections of text not to exceed two paragraphs, may be quoted without explicit permission provided that full credit including Cnotice, is given to the source. 
Time in Purgatory: Determinants of the Grant Lag for U.S. Patent Applications

David Popp, Ted Juhl, and David K. N. Johnson

NBER Working Paper No. 9518

February 2003

JEL No. O3, O32, O34

\section{$\underline{\text { ABSTRACT }}$}

The impacts of two recent changes in US patent policy depend on the length of time it takes for an invention to go through the examination process. Concerns over the distributional effects of these changes were expressed during policy debates. We use data on U.S. patent applications and grants to determine the factors influencing the length of the patent examination process. We augment this analysis with interviews of patent examiners, leading to a better understanding of the examination process. Our analysis finds that differences across technology are most important. Inventor characteristics have statistically significant effects, but the magnitudes are small.

David Popp

Department of Public Administration Center for Technology and Information Policy

The Maxwell School

Syracuse University

400 Eggers Hall

Syracuse, NY 13244-1090

and NBER

dcpopp@maxwell.syr.edu

Daniel K.N. Johnson

Department of Economics

Pnedelton East

Room 415

Wellesley College

106 Central Street

Wellesley, MA 02481-8260

djohnson@wellesley.edu
Ted Juhl

Department of Economics University of Kansas

213 Summerfield Avenue

Lawrence, KS 66045

juhl@ku.edu 


\section{Time In Purgatory}

O thou full man, barley-bread pleases thee not.

She is my sweetheart who appears ugly to thee.

To the huris of paradise purgatory seems hell.

Ask the denizens of hell. To them purgatory is paradise.

Sheykh Moslehodd Sadi, Gulistan Chapter 1 Story 7

The grant lag, or period of time between an initial patent application and its final granting, can often be seen as a period of purgatory for the applicant. It is a time of uncertainty, not only regarding which (if any) claims will be protected, but about the length of time until that decision is finalized. However, this paper argues that the length of the grant lag is not entirely exogenous to the applicant, but instead is partially determined by characteristics of the application itself. In fact, we must remember that a shorter lag is not always preferable, as the opening quotation conveys.

Because of recent changes to U.S. patent law, the length of examination time has become an important factor. First, as a result of the Uruguay round of GATT, in 1995 the U.S. changed the duration of patent protection to coincide with other industrialized countries. Before 1995, the length of patent protection in the U.S. extended for 17 years after the date of issue. After 1995, protection extended for 20 years, but from the application date. Thus, whether a patent receives more or less protection under the new rules depends on whether the examination process takes more or less than three years. To the extent that inventor characteristics may influence the grant lag, this policy change may have important distributional effects.

Similarly, the American Inventors Protection Act (AIPA) of 1999 also includes changes that are influenced by pendency time. Unlike other countries, patent applications in the United States have traditionally been kept secret until the patent is granted. The AIPA changed US law so that all pending applications are published after 18 months, as is done in most other countries. 
Thus, patents that take more than 18 months to be granted lose some secrecy as a result of the AIPA.

During debate over the AIPA, independent inventors argued against publication of patent applications, arguing that they would be hurt more than large firms. With more limited legal resources, independents and small firms are less able to obtain redress if a larger firm infringes, and are less able to keep pace if larger firms attempt to invent around the patent. As the period of secrecy shrinks, and the applications are published before being granted, independent inventors fear that they will become even more vulnerable. In particular, they argued that the patents most affected by early disclosure are breakthrough inventions, often made by independent inventors, that often require a long time to progress from application to granted patent.

There have been several recent pieces in the economics literature which explore patent grant lags, but none that look at how the grant lag varies by patent characteristics. Thus, these studies can tell us about the overall impact of the aforementioned policies, but cannot tell us anything about the distribution of effects. For instance, Johnson and Popp (forthcoming) clearly show that patents with long lags are more cited by subsequent inventors, so in some sense can be considered more socially valuable. Thus, the concern that breakthrough inventions are impacted more by early disclosure has merit. However, although their work reveals that more valuable patents are affected more, it does not reveal who is affected by this change. Furthermore, Johnson and Popp also show that knowledge diffusion effectively begins with publication, so in a system where publication occurs only at the grant date, shorter grant lags would speed subsequent innovation and reduce duplicative effort. ${ }^{1}$

\footnotetext{
${ }^{1}$ While the American Inventors Protection Act of 1999 requires that most patent applications be published after eighteen months regardless of grant status, that requirement is waived for U.S. applicants who agree not to pursue
} 
King (2002) provides an institutional view of the U.S. Patent Office, using internal timesheets and activity reports to confirm that while inputs to the U.S. patent examination process have remained roughly constant over time, there have been ever-increasing examiner workloads. As a result, grant lags have risen and other measures of output quality (from the point of view of the U.S. Patent Office) have fallen. GAO (1996) reported that "patent pendency is likely to become a more important concern to those outside PTO (the Patent Office) in the future."

This paper enters that literature with some new results, based on interviews with U.S. patent examiners and on patent data themselves. We outline the granting process, paying special attention to the elements which add significantly to grant lags, including discussion of how the process has changed over time. Although a primary interest is learning how different types of inventors are affected by the examination process, to do this it is important to control for other features of the patent that affect pendency. Thus, we also highlight some institutional factors responsible for different grant lags between technology classes. Most importantly, we use quantile regression analysis to identify the sensitivity of grant lags to attributes of the applications themselves, with an interest not just in the average relationships, but also in how that sensitivity changes across the spectrum of patents.

Section II outlines the granting process of the United States Patent and Trademark Office (USPTO) and describes the results of interviews with examiners from that office. Section III presents summarizes the data, while Section IV presents quantile regression results. Section V concludes and offers suggestions for further research.

patent protection outside of the U.S. Thus, a shorter grant lag would still have a disclosure effect for purely domestic U.S. patents. 


\section{The USPTO granting process}

During the fall of 2002, we interviewed five USPTO officers in varying levels of authority, all with extensive patent examination experience. From those officers ${ }^{2}$ we obtained a detailed view of the institutional process, and a review of the major issues which determine the grant lag for any given patent.

Upon arrival at the USPTO, an application is reviewed by the Office of Initial Patent Examination (OIPE) to ascertain that all required disclosures, fees and claims are included. Any searches for prior art, as completed by the applicant or his attorney, are included in this packet. If an element is missing or incorrect, an additional fee is assessed and processing is delayed until the application is correctly completed. The usual delays at this point are due to incorrect fee submissions (an applicant using old fee schedules or failing to add charges for additional claims) or missing chemical sequence information for biotechnology applications (required since 1990).

When the application is complete, an application wrapper is assembled and the USPTO clock starts. The USPTO guarantees processing in three years of less, with exceptions labeled "failure." Since patent protection lasts for 20 years from the application date, patents which take longer than three years due to problems at USPTO are extended without cost to the applicant. However, stretching of the process due to applicant (in)action is not included. Once the wrapper is attached, an examiner at OIPE assigns the patent to a main U.S. patent classification (of which there are currently 428). Based on that classification, the patent is then sent to one of 7 technology centers: ${ }^{3}$
- 1600
Biotechnology, Organic Chemistry
- 1700
Chemical and Materials Engineering

\footnotetext{
${ }^{2}$ We retain the anonymity of these officers, recognizing that their opinions are not necessarily those of the USPTO, and were conveyed to us solely for the purposes of this research.

3 For a complete list of both the Technology Centers and the individual Art Units within, see http://www.uspto.gov/web/info/pat-tech.htm.
} 
- 2100 Computer Architecture, Software, \& Electronic Commerce

- 2600 Communications

- 2800 Semiconductors, Electrical and Optical Systems and Components

- 3600 Transportation, Construction, Agriculture, National Security and License and Review

- 3700/2900 Mechanical Engineering, Manufacturing, and Products and Designs

A processor at the technology center ensures that the initial OIPE-assigned classification is correct, assigns a more precise subclassification, attaches any relevant amendments, and assigns it to a docket for the center. Technical support staff in the technology center complete this initial processing.

Within each center are Individual Art Units, composed of nine to twenty examiners with similar fields of technological expertise. Directors of the Art Units divide up the docket for the center, assigning each patent to a specific examiner in their Unit. The application enters an examiner's electronic queue and waits for the backlog to clear. At any given time, an examiner has an average of three to six amended documents on his docket (with a turnaround time ranging from 10 days to two months, depending on the complexity of the amendments) on the docket, plus new applications. This queuing time is the most time-consuming portion of the application process, as current backlogs in some technologies are in excess of two years. Backlogs are driven by the number of filings in a given technology, and problems arise when applications arrive too quickly to keep up, often in unexpected or faddish areas. Not only is it a challenge for the USPTO to hire more examiners in unexpected technological areas, but it is often a challenge to retain those experts it has, when lucrative private sector opportunities call. This is particularly a problem in emerging scientific fields, where a Ph.D. in the scientific field being examined is helpful. In some years, Centers have hired 100 new examiners, only to see less than half of them remain by the end of the same year. When combined with the multi-year maturation process for examiners, hiring is a costly exercise. 
There are official goals for the number of hours each examiner will spend on an average application, with incentives for superior performance. Usually the productivity goal is expressed as the number of "balanced disposals", or any two of the following for an application docket:

a) first action - initial communication to applicant (see below)

b) abandonment - the application is discontinued

c) allowance - the application is accepted by the examiner, recommended to be granted

d) interference count - competing claims by several applicants

e) examiner answer - sent to higher court or authority, or recommended denial

The productivity goal differs by examiner rank. In most technology centers, the base productivity goal is 17 hours, which is then adjusted up or down based on each examiner's level of experience. Recognizing that the complexity of computer and biotechnology patents require more examination time, the USPTO allots more time for patents at these technology centers. For example, the base productivity goal for computers is 31.6 hours. Naturally, supervisors give authority to spend additional time on more difficult applications, and they use discretion in assigning those applications to the more junior examiners in their Unit. In addition, they usually build up expertise in one or more subfields in particular examiners, to exploit comparative advantage within the Unit. However, they may also reassign cases to keep backlogs consistent. In rapidly changing fields, or fields where it is difficult to hire and retain examiners, it is a perpetual challenge to maintain Unit expertise in each subfield.

Each Art Unit sets goals based on standard work weeks with their full staff, but Congressional goals are set for the USPTO as a whole, and tend to run five to fifteen percent higher in terms of numbers of disposals. Since the plan is always to meet the Congressional goals, performance bonuses are integral parts of the system. 
A first action is guaranteed within 14 months of application, and begins with the examiner construing the claim, determining what is being claimed in order to develop a search for prior art. This can be completed in five minutes for a well-written application, but may take several hours for a poor one, especially in a complex technology. Next, the examiner begins with a simple search for the state of the art in the technology, including the mandatory search through the US patent class to which the application belongs. The search usually extends to nonU.S. patents and non-patent literature (e.g. trade journals) for which each Technology Center has a dedicated staffed library, called the Science and Technology Information Center (STIC). Biotechnology has an additional set of research tools, including online services (journals, MedLine, BioSys, STN Dialog, Chemical Abstract Service, Agricola, USDA, germplasm databases) and access to the locally situated National Institutes of Health libraries. The Computer Technology Center has a separate Electronic Information Center, and provides mandatory training in non-patent literature searches through databases including copyrights. ${ }^{4}$ Delays may build up around the end of the fiscal year, as firms file amendments to beat deadlines, but researchers at STIC can usually respond to any request within a few days. That response time delays the application only marginally and does not count on an examiner's productivity clock. The first action ends when the examiner has communicated to the applicant all problems with the application, including challenges of art repetition (too close to prior art) or enablement (too little disclosure). At this point, the USPTO clock stops, and the applicant has six months in which to respond in order to keep the application's priority.

\footnotetext{
${ }^{4}$ Non-patent literature searches are particularly important for computers and software. Since patenting in these fields have just recently taken off, the prior art often consists of innovations that were not patented. As a result, in the Computer Architecture, Software \& Information Security technology center, searches of the non-patent literature are mandatory.
} 
Along with queuing time, communication delays are the most important component of the grant lag. Each time that amendments or clarification are required from the applicant, months elapse in the exchange - the applicant has at most six months to respond to the USPTO, the examiner has at most two months to respond to the applicant. While most of an examiner's productive time is spent on first actions, time which includes the initial search for relevant patents or non-patent literature, often a substantial amount is also spent reworking and updating searches for cases where amendments have delayed the process. Sometimes the amendments are severe enough to require an entirely new first action.

The scientific qualifications of examiners differ greatly by technology, with doctorates highly desirable in some fields and unnecessary in others. Legal training is provided by the USPTO during the first two months of employment. During their first five or six years at the USPTO, junior examiners do not have signatory authority. After this initial period, they may elect to join the "signatory program", and are promoted to GS-13. A one-year probationary signatory period begins. In the first six months as a GS-13, an examiner is allowed to sign off on initial actions, but not final actions. After review, the examiner is given a signatory position with another six month trial period for final actions. Again, after review, the examiner may be granted full signatory privileges, a permanent promotion.

When asked for the attributes of an application which most delayed processing, USPTO officers listed four general topics: the type of technology, the breadth of the application, the nature of the applicant, and the list of references. We explore each in turn. 
i) Type of technology

There are clearly large variations between technologies, with greater complexity of applications in biotechnology and computers than in other fields (examiner productivity standards recognize this explicitly). More importantly, by all accounts that complexity has been rising rapidly in absolute and relative terms.

For example, currently chemical sequences are doubling in size and complexity every 915 months. While computational speed has been rising as well, making processing of searches easier, speed has not kept pace with applicant complexity. The result is that search times have risen from roughly 10 minutes (a decade ago) to 20-30 minutes now. A decade ago, one inch of paper would list all known "hits" in the patent and non-patent literature, while now the total runs 4-6 feet of paper, or 1 inch for the top 15 hits alone. Complexity problems are particularly acute in cross-disciplinary fields, such as bioinformatics (the threshold of computing and biochemistry), as applications require examiners with expertise in two or more disparate technologies. While it is possible to parse an application between examiners, that presents additional coordination challenges which also delay processing.

As a mixed blessing, the time guidelines for examiner productivity have not changed for more than fifteen years. On one hand, the USPTO seems to be expecting the grant lag to remain constant if the examiner-to-application ratio remains constant. On the other hand, we might infer that examiners must be more experienced, more knowledgeable, or less thorough than they once were.

There was mixed opinion about whether examination is easier or harder in a "crowded technology". While crowded fields make the search for prior art quick, they make reading for competing claims more painstaking. Interference delays usually occur in densely packed fields, 
but may occur in open fields as well, with equally devastating delays. ${ }^{5}$ For example, early biotechnology firms often shared laboratory space, researchers and even legal counsel, leading to long interference delays in a relatively young and uncrowded technology.

Different requirements across technologies may also lead to differences in pendency time across technologies. For example, since October of 1990 all applicants for biotechnology patents have been required to list chemical sequences for claims regarding polynucleotides and polypeptides. A software package was designed to help applicants prepare the correct information, and the USPTO has a counterpart program which converts paper documents to an electronic version of the sequence information. While the goal was to make searching for prior art quicker (via computer), it created a huge bottleneck in the process, along with a learning curve for applicants, their legal representation, and examiners. Many applications during the first year were rejected by OIPE for lacking sequence information, with each communication adding up to six months to the process. The ruling on sequences was revised in late 1998, and has undergone several minor revisions since that time.

When a patent claims two or more independent and distinct inventions, the examiner may require that the applicant choose just one of the inventions to qualify for patent protection. This is known as restriction. If the applicant wishes, he or she may then file a divisional application for the remaining invention. According to examiners in the field, restrictions (as well as subsequent related or divisional applications) are definitely more common in relatively complex technologies like computers. While longer lags may not be due directly to greater complexity, technologies which incorporate a variety of inventions or encompass a broad scope tend to require more related applications, and more paperwork means more processing time.

\footnotetext{
${ }^{5}$ Interference claims occur when two or more patent applications make the same claim. In this case, only one applicant can be awarded a patent for the claim.
} 
Subsequent divisions and related applications are also more common in the chemical and biotechnology areas because of the way in which those technologies need to be claimed. Claims in these fields which have a biological or chemical resemblance to other granted or pending claims (in a similar Markush group, similar nucleotide sequence, or share a genus-species relationship) require examiners to review all relevant claims in the entire category.

Technologies which rely more heavily on patents as prior art (e.g. mechanical devices) are easier to examine, in that examiners can obtain the information they need more readily from other patents than from non-patent literature. Since pre-existing patents present an obstacle to new patents, they make rejection decisions easier. Moreover, since patents are required to include

"a written description of the invention, and of the manner and process of making and using it, in such full, clear, concise, and exact terms as to enable any person skilled in the art to which it pertains, or with which it is most nearly connected, to make and use the same, and should set forth the best mode contemplated by the inventor of carrying out his invention" (United States Code Title 35, Section 112)

it is easier to compare the claims of a new patent with those of prior patent art than with those of non-patent literature.

Examination is also more difficult for patents without an obvious "searchable key word." That may be due to the nature of the innovation itself (e.g. process patents are more difficult than product patents, as examiners are searching for similar verbs instead of similar nouns). It may also be due to the nature of the field (e.g. a new field with non-standardized terms is more difficult to search). 


\section{ii) Breadth of application}

Unequivocally, broader applications are more time-consuming, although an application of many well-written claims may be faster than an application of a few poorly-written ones. In general, since each claim must be researched and evaluated, more claims require more time. In particular, applications with "unduly multiplied" claims require a large amount of communication and clarification. Overly broad or multiple claims can be an indicator of either an inexperienced or very experienced applicant. Inexperienced applicants often merit a quick first action, followed by a lengthy series of subsequent actions and communication. More strategically broad claims, filed by very experienced applicants or very experienced attorneys, require an enormous amount of communication as well, but for different reasons. In fact, experienced applicants (or legal representation) often aim to submit many independent claims, deliberately of different scope. The object is to form a portfolio of claims, offering the applicant choices about which to litigate, which to pursue through the entire patenting process, and which to renew to full term. By creating a choice set, the applicant is not limited by the financial costs imposed by a claim of large scope, so does not risk forfeit of all intellectual property associated with the application if one claim is lost. ${ }^{6}$

iii) Nature of applicant

Applicant experience with the patent system was consistently listed by examiners as a critical determinant of the grant lag, and is linked to the clarity and breadth of the claims presented.

\footnotetext{
${ }^{6}$ As a result of this, the patent office is currently considering a proposal to charge inventors extra for claims in excess of 20 .
} 
Foreign applications are seen as taking no longer or shorter than domestic applications, with the exception of translation difficulties. However, any communication requires more time than for a domestic application, as it is usually routed through two attorneys, one in each nation involved. There may also be formatting issues, as European-style claims are unacceptable in the U.S. and Patent Cooperation Treaty (PCT) applications often involve multiple claims, so might be divided in the U.S., perhaps even to be processed by separate examiners. There are regulations governing the division of PCT documents in particular, so applications may take slightly longer for logistical reasons.

There is no evidence from our interviews that small or independent inventors bear a longer lag than firms do, holding experience levels constant. In fact, an experienced attorney can even make up for an inexperienced inventor/applicant, so any differences between small and large firms may condense to a difference in legal counsel. There are also resources available to independent inventors, to help with the application process.

\section{iv) List of references}

When a patent is granted, it contains citations to earlier patents that are related to the current invention. These citations are analogous to references in a journal article, conveying a list of ideas that the inventor may have accessed during the inventive process. To aid the patent examiner's search, the applicant is required to list any references to previous patents that are related to the current invention. Furthermore, should the examiner finds previous inventions that narrow the scope of the current patent, he must list those patents as well. Patent citations narrow 
the scope of a new patent by placing cited patents outside the realm of the current patent, so it is important for the legal system that all relevant patents be cited. ${ }^{7}$

There was unanimous agreement that a long list of references is not preferable to a short list, but that it is the quality, not quantity, of the references that truly matters. It is quickly obvious to the examiner if the reference list includes only the obvious prior patents, or everything the applicant knows about the technology, rendering the entire reference list virtually useless. An overly long list may simply be roughly filtered by the examiner, with only the more recent references read. All of the examiners we interviewed complained about applications which arrive with boxloads of supporting references. Examiners often suggested that an application with no references at all would be preferable, since the examiner could research it himself instead of being saddled with the existing reference list to edit.

At the very least, granted patents with many citations are a sign that the examiner needed to search through substantial prior art (regardless of whether the initial reference list was accurate and informative) before ruling on the application. Finally, computerization of patent records has made finding such patent references easier, both for examiners and applicants. Thus, the average number of citations per patent has risen over time, muddying the waters about how to compare the length of reference lists over time.

Thus it seems clear that there are identifiable characteristics that may be associated with longer grant lags, at least some of which are within the control of applicants. In the next section, we turn to the empirical evidence relating those characteristics to observed grant lags.

\footnotetext{
7 "Outside the realm" means that a patent holder cannot file an infringement suit against someone whose invention infringes on qualities also included in the cited patents.
} 


\section{Data}

Our analysis focuses on all utility patents granted in the United States between 1976 and 1996. Descriptive patent data are from the NBER patent database (Hall et al., 2001). ${ }^{8}$ During this time period, only granted patents were published in the United States, so applications that did not become patents are thus not part of the public record. ${ }^{9}$ After removing observations with clearly erroneous data (such as grant dates before the application date), we have 1,653,854 patents in our data set. To calculate the full pendency time of each application, the USPTO provided us with the date of the earliest related application for each patent, as opposed to the published application date on the front page of each patent, which reflects merely the arrival date of the current version, thus omitting time spent in previous revisions. In addition, they provided data on the number of claims, drawings, and sheets for each patent.

Looking first at pendency time itself, Figure 1 presents the distribution of grant lags through the first 12.5 years, which covers $99.9 \%$ of all patents. The actual tail of the distribution continues beyond what is shown in the graph, as our data set includes patents with lags up to 1143 months long. As Table 1 indicates, the mean grant lag is 28 months, but with such a highly skewed distribution, the median grant lag is just 23 months.

Our goal is to determine which features of a patent affect pendency time, and we focus on the following elements. First, we use several variables to measure the complexity of each patent. As noted earlier, each patent consists of several claims that describe the features of the invention and how it improves upon the prior art, and examiners indicated that the number of claims have a positive effect on pendency time. Similarly, we would expect the number of sheets and drawings

\footnotetext{
${ }^{8}$ In addition to data taken from the NBER web site, we also use additional data on the type of assignee made available to the authors. Unlike the other data, this variable is only complete through 1996. We thank Adam Jaffe for making this available to us.
} 
included to increase pendency time, so each are included in our analysis. ${ }^{10}$ As Table 1 reports, the average patent has roughly 12 claims, less than four sheets, and seven drawings.

Examiners also voiced a possible positive relationship between pendency time and the length of the reference list appended to a patent. Since an examiner must search all prior art in the field to ensure novelty, we would expect patents with more citations to take longer to be processed. ${ }^{11}$ As noted in Table 1, while the average patent has only seven references, an average of one citation per claim, there is a wide range to patents citing over four hundred references. To control for the rise in the length of citation lists over time, we include in our regressions an interaction term as the product of the issue year (defined as the last two digits of the year of issue) and the number of patent citations on the patent.

Using data on patent assignees ${ }^{12}$ from the NBER database, we identify the type and origin of each assignee as follows:

Assignee types: Unassigned, Individual, Firm, Government, University, Hospital, NonGovernment Research Lab, Non-Profit Organization

\footnotetext{
${ }^{9}$ Since the passage of the American Inventors Protection Act of 2000, applications are now published 18 months after the initial filing, unless the inventor agrees not to file for patent protection abroad.

${ }^{10}$ Actual correlations between these variables are smaller than expected. For example, the correlation between claims and drawings is just 0.17 , and between claims and sheets is 0.15 . Drawings are often used to illustrate technical concepts that are not easily summarized in writing. Thus, both can serve as an indicator of the complexity of a patent, yet there need not be a one-to-one correspondence between them.

${ }^{11}$ Note that the data set only includes citations made to other granted U.S. patents. This is not the only source of prior art. In addition, patents granted in other nations and other published scientific literature (called NPL, or nonpatent literature, by examiners) must be searched. Although counts of such references are not included in our data set, counts of references to U.S. patents provide a good measure of the amount of prior art related to the invention. An examiner need only find one existing reference that anticipates an application's claim to invalidate or narrow said claim. Since examiners are most familiar with U.S. patents in their field, examiners typically begin by searching the prior art in U.S. patents first. Thus, in most fields, citations to U.S. patents are the most frequently used prior art.

${ }^{12}$ Typically, the front page of a patent lists both the inventors, who are responsible for creating the invention, and the assignees, who hold the property rights bestowed by the invention. Occasionally, such as in the case of an independent inventor, these will be the same. More typically, the assignee(s) will be the firm or organization for which the inventor works. For example, most academic institutions require faculty to sign an agreement transferring to the university the rights to any patents derived from the faculty member's work. In this case, the faculty member would be the inventor, and the university would be the assignee. In some instances, assignment has yet to be made when the patent is granted. These patents are classified as unassigned.
} 
Home country of assignee: United States, Japan, Germany, France, United Kingdom, Canada, Other member states of the European Patent Organization, Other countries

In addition, we use the assignee codes provided in the NBER database to identify all patents granted to each assignee since $1963 .^{13}$ We then create an experience variable by calculating the number of successful patent applications filed in the three years prior to the application date of each patent in the data set. ${ }^{14}$ The mean of the experience variable, shown in Table 1, is 320. Note, however, that this is also a highly skewed distribution, as the median experience value is just 25 .

Table 2 presents descriptive statistics by assignee type. 78 percent of patents are assigned to private firms, either from the U.S. or abroad while another 18 percent of patents are unassigned at the time the patent is published. Patents assigned to individuals make up just one percent of our sample. Figure 2 shows that this distribution has remained stable over time. While the percentage of university patenting has risen over time, as a result of the 1982 BayhDole Act, they never rise above two percent of our sample.

Note that there are some significant differences among variables across assignee types. In particular, patents from hospitals, labs, and universities take longer to be granted. Patents from the government contain fewer citations than other patents, perhaps indicating that they are more "basic," in that they occur in less crowded technology fields. However, such patents also contain fewer claims, so that the number of citations per claim is similar to other patents.

\footnotetext{
${ }^{13}$ We use successful applications only, as these are the only patents contained in our data set. However, we base the experience variable on application dates in order to proxy for the experience at the time the application was filed. Presumably, experience at the time of filing, rather than at the time of grant, would better enable the applicant to avoid common errors in the application process. Unfortunately, we are unable to construct an experience variable for independent inventors or unassigned patents. All independent inventors are given a single code in the NBER database, and, of course, all unassigned patents are similarly grouped.

${ }^{14} \mathrm{We}$ also tried experience variables using patents from the previous year or previous five years. Results were similar in all cases.
} 
We can describe the technology field of each patent using the USPTO patent class and category definitions defined in Hall et al. (2001), placing each patent in one of 10 technology groups: Chemicals, Organic Chemicals, Organic Chemistry, Computers, Software, Biotechnology, Medical, Drugs, Mechanical, Electrical, and Miscellaneous. As Figure 3 shows, the Chemical, Electrical, Mechanical, and Miscellaneous fields contain the most patents but the shares accounted for by other technologies have been rising. This is particularly true for Biotechnology, Computers, and Software, where court rulings in the 1980s and 1990s cleared the way for patents.

The differences in pendency time across groups are almost entirely predictable, as they reflect the underlying complexity values assigned to them by the USPTO for examiner productivity measurement. The average grant lag ranges from 25.2 months for miscellaneous patents to 1.77 times that amount, or 44.6 months for biotechnology. However, recall that the average examination times allocated for miscellaneous patents is $12-17$ hours, and the average time allocated for biotechnology is 1.75 times that amount, or 21-29 hours. In short, the USPTO productivity guidelines appear remarkably well constructed, leaving only the surprise that one hour of examiner time translates almost exactly into two months of pendency time.

There is little difference in the number of claims across technologies, but bigger differences in the number of citations. Also, note that drawings are important for fields such as computers (which have an average of 6.7 claims, but 10.6 drawings), and are less so for others. Interestingly, even though fields such as software and biotechnology are relatively new, the mean (and median) experience levels in those fields are quite high due to high numbers of applications in recent years. 
We also consider differences across nations of origin, displayed in Table 4. Fifty six percent of our sample patents are assigned to U.S. entities, Japan is next at 18 percent, and Germany ranks third at 8 percent. With the exception of Canada and Other countries, nearly all foreign patents assignees are firms (e.g. 96 percent of Japanese patents are so assigned). Grant lags vary somewhat by country, although not as much as across technology or inventor type. Surprisingly, the mean grant lag of U.S. patents (28.8) is second highest. While U.S. patents contain more citations than other patents, this may be an artifice of the data, since we count only citations to other U.S. patents. As some citations are made by the applicant, it is likely that foreign applicants tend to cite non-U.S. patents more frequently, which is not captured by our measures. Of course, there are also interesting differences across technologies (e.g. percentage of computer patents from Japan is twice as high of the other countries, France and the UK have a higher percentage of drug patents than other countries).

Finally, as Figure 4 shows, the average grant lag has also changed fairly dramatically over time. There are several reasons for this - for example, budget cuts at the USPTO in 1979 led to fewer examinations being done that year (Griliches, 1990), and the resulting backlog slowed the application process for several years, resulting in higher mean grant lags during the early 1980s. In recent years, a rapid increase in patent applications has once again increased pendency time. To control for such changes over time, our regressions include dummy variables for each issue year.

\section{Regression Results}

To determine the effect of these characteristics on the grant lag, we use a hazard regression. The specification of the regression is: 


$$
\operatorname{lag}_{i}=e^{\left(\mathbf{x}_{\mathbf{i}} \boldsymbol{\beta} \varepsilon_{i}\right)}
$$

where $\operatorname{lag}_{i}$ represents the grant lag of patent $i$, and $\mathbf{X}_{\mathbf{i}}$ represents the vector of patent characteristics defined in section $\mathrm{X}$. Taking logs to linearize the model gives us:

$$
\log \left(\operatorname{lag}_{i}\right)=\mathbf{X}_{\mathbf{i}} \boldsymbol{\beta}+\varepsilon_{i}
$$

We begin with ordinary least squares (OLS) results, which fit the model based on the conditional means of the independent variables. However, since the distributions of both the grant lag and many of the independent variables are quite skewed, such regression results may inadequately reflect the behavior of patent characteristics at other points on the distribution. Thus, we also use quantile regression techniques to provide a more complete picture of the behavior of the model.

\section{A. OLS Regression Results}

Table 5 presents the results of an OLS regression on the patent grant lag of the variables discussed above. Because of the log-linear form of the hazard regression, column 3 shows the calculation $e^{\beta}-1 .^{15}$ For each dummy variable, $e^{\beta}-1$ tells us the percentage increase from the base for a patent having that characteristic. For other variables, $e^{\beta}-1$ tells us the percentage increase for a one-unit increase in that variable. To aid interpretation, we also present the total change based on the mean and median values for the continuous independent variables.

The signs of most coefficients in Table 5 are as expected. Given that we have over 1.6 million observations, nearly every parameter estimate is statistically significant. Nonetheless, as we will see below, many of the estimated effects are of a negligible magnitude. Unassigned and government patents are somewhat faster than applications filed by firms, but successful

\footnotetext{
${ }^{15}$ For the constant, we simply present $e^{\beta}$, which tells us the estimated grant lag for a hypothetical base patent with no citations, drawings, or sheets, assigned to an inexperienced U.S. firm, in the electrical field, and granted in 1976.
} 
applications from other assignee types take longer to process. Except for patents from universities, hospitals, or laboratories, the magnitude of this effect is small, albeit significant. For instance, a patent application from an independent inventor takes just two percent more time. For the mean lag, this is an increase from 28.37 to 28.94 months, or approximately 17 days. We can strongly reject the null hypothesis that assignee types have no effect, as the F-statistic for this test is 543.82 .

Country effects are generally as expected, with one counterintuitive twist. Although the average grant lag for U.S. patents was higher than most other countries, this effect is apparently a function of other patent features. Only patents from Canada and other non-EPO countries go through the process more quickly, and it is a small advantage - just two percent in each case. Still, this is a surprising result. If it is a translation issue that separates Canada from the EPO, then why is it faster than the U.S., and even more striking, faster than the United Kingdom by a large margin? In fact, United Kingdom patents experience the biggest increase in time, as they take nine percent longer. Once again, the overall differences are statistically significant. The Fstatistic for the null hypothesis that all country coefficients equals 0 is 491.56 .

Year effects are also as expected. Because of the backlog resulting from USPTO budget cuts in 1979, patents granted in the mid-1980s bore the longest pendency periods. Grant lags shortened in the late $1980 \mathrm{~s}$, aided both by the reduction of the backlog and the computerization of patent searches. By the late 1990s, grant lags begin to increase again as application volume rose. Even after controlling for increases in applications from technologies such as biotechnology and computer software, patents granted in 1996 took nine percent longer than the base year. Increases in patenting activity across all sectors have placed added strain on the limited resources available at USPTO. 
With the exception of the number of sheets, which is insignificant, the continuous variables all have the expected signs. Increases in number of citations, claims, and drawings all increase examination time, all with small marginal effects. The largest increase is for citations, where each additional citation adds 5 percent to the examination time. As expected, additional experience speeds the examination process, but results are only significant at the 10 percent level, and the magnitude of the effect is trivial. Even the average experience of 320 patents in the last three years reduces the grant lag by less than one percent. ${ }^{16}$

By far the biggest differences in examination times come across sectors. As discussed in the interviews, technologies such as biotech and computers are more complex, and require more examination time. Indeed, we see that, controlling for other factors such as longer reference lists, biotechnology patents still take 69 percent longer than electrical patents, and drug patents take 43 percent longer. Software and organic chemistry patents each take 30 percent longer. Note that there is little difference across the more traditional technology classes of electrical, mechanical, and miscellaneous technologies.

\section{B. Quantile Regressions}

OLS regression estimates give the change in the conditional mean of $\log$ (grantlag) if we change a variable by one unit. However, given that the distribution of grant lags is highly skewed, and that patents in the upper tail are those most affected by policies that relate to the

\footnotetext{
${ }^{16}$ One possible concern is endogeneity between the experience variable and other patent characteristics. For instance, more experienced inventors might know how to best craft a patent for quick review, and thus adjust features such as claims and citations accordingly. Unfortunately, lacking a good instrument for experience, we are unable to directly test for such endogeneity. However, we did do two indirect tests which support including each variable in the regression. First, omitting experience from the regression has little effect on the other parameter estimates. Second, we regressed each of the explanatory variables on the number of claims and citations. Although statistically significant, the magnitude of the effect is essentially zero. An additional patent of experience decreases citations by 0.00037767 , and claims by 0.00005568 . Thus, even a patent with the maximum experience $(3755$ patents) would only have 0.2 fewer claims.
} 
grant lag (such as basing protection on the priority date, rather than the issue date), looking at the behavior of patents throughout the distribution is valuable.

Quantile regression allows examination of inter-variable relationships at various parts of the conditional distribution. For example, as noted above, experience has no effect on the conditional mean (the OLS coefficient is not significant at the 5\% level). However, as we will see below, the lower and upper parts of the conditional distribution are affected. In other words, those patents that tend to be quick (given conditioning variables) are going to be quicker for experienced inventors, and those that tend to take a long time will take longer with experienced inventors.

A formal explanation of quantile regression follows (for more, see the recent survey by Koenker and Hallock, 2001). Suppose we would like to calculate the median of a set $\left\{y_{1}, y_{2}, \ldots, y_{N}\right\}$. It is well known that the median of the set is the solution to minimizing the problem

$$
R(\xi)=\sum_{i=1}^{N} \rho_{.5}\left(y_{i}-\xi\right)
$$

where $\rho_{\tau}(\varepsilon)=\varepsilon(\tau-I(\varepsilon<0))$ and $I$ is the indicator function taking the value of 1 if the argument is true. Koenker and Bassett (1978) use this function for general values of $\tau$ to find "quantiles" of the distribution, so that the median is only a special case. Hence, to find the $95^{\text {th }}$ percentile, one chooses $\tau=0.95$ and solves the above minimization problem for $\xi$.

To find the sample mean of $\left\{y_{1}, y_{2}, \ldots, y_{N}\right\}$, we minimize

(4) $\sum_{i=1}^{N}\left(y_{i}-\mu\right)^{2}$

and we find the conditional mean by minimizing 
(5) $\quad \sum_{i=1}^{N}\left(y_{i}-x_{i}^{T} \beta\right)^{2}$

with respect to $\beta$. Analogously, Koenker and Bassett show that conditional quantiles can be estimated by minimizing

$$
\sum_{i=1}^{N} \rho_{\tau}\left(y_{i}-x_{i}^{T} \beta\right)
$$

so that the estimated conditional $\tau^{\text {th }}$ quantile is $x_{i}^{T} \hat{\beta}(\tau)$. Each coefficient of $\beta(\tau)$ represents the effect of a one unit change in the independent variable on the conditional $\tau^{\text {th }}$ quantile of the dependent variable $y_{i}$. Hence, it is possible to estimate parameters over a range of quantiles and examine how the independent variables affect various parts of the distribution. This is in direct contrast to OLS estimators, where each coefficient of $\beta$ measures the response of the conditional mean to a one-unit change in the corresponding independent variable. In this section, we estimate all parameters and provide standard errors for quantiles 0.05 to 0.95 using 0.05 increments.

Figure 5 presents the quantile regression results for each parameter. ${ }^{17}$ Each figure presents both the estimated parameter value for each quantile and the $95^{\text {th }}$ percent confidence intervals for the estimates. For easy comparison, the figures also show the OLS estimates and $95^{\text {th }}$ percent confidence intervals.

On each graph, the $x$-axis represents quantiles of the error term for each patent. That is, even after controlling for all factors in our regression, some patents will take a shorter time to be examined, so have errors in the lower quantiles. Similarly, patents with errors in the upper quantiles take a long time to be examined, even after accounting for the proposed list of explanatory variables. The $y$-axis of each figure depicts the result of a one-unit increase in the 
independent variable on the log of the grant lag. For example, the figure for independent inventors relates that, up until the $70^{\text {th }}$ percentile of the error distribution, the effect of being an independent inventor is constant. In each case, it adds about two percent to the grant lag, and the parameter value is consistent with the OLS estimate of 0.023 . However, for patents with errors in the upper quantiles (that is, patents that, even controlling for each explanatory variable, simply take longer anyway), being an independent inventor has a much stronger effect.

Comparing the quantile results to the OLS results discussed above, we see that in many cases, the quantile results provide substantial additional information about the behavior of grant lags. We begin by looking at the effect of the assignee, recalling that the excluded variable is the firm dummy. Note that the behavior in the upper tail of the distribution is significantly different from lower levels. For instance, in general, government patents go through the process somewhat faster. However, in the very upper quantiles, government patents take much longer. At the $75^{\text {th }}$ percentile, a government patent application is processed five percent faster than other patents. The results are similar at lower quantiles. However, at the $95^{\text {th }}$ percentile, a government patent is processed 22 percent slower than other patents. The OLS results pick up neither extreme, as they find government patents to be just two percent faster than other patents. A likely interpretation is that patents with extremely long grant lags include patents that were kept secret for reasons of national security. In testimony before Congress in 1994, Patent Commissioner Bruce Lehman reported that of the 627 patents issued from 1971-1993 that fit the definition of a submarine patent (that is, an application that is kept active at the USPTO for several years before surfacing), $41 \%$ were patents held by the U.S. government and kept secret for security reasons. Another $12 \%$ were privately held patents that the government ordered

\footnotetext{
${ }^{17}$ To save space, we have omitted plots of the year dummy variables. These plots are available from the authors.
} 
secret for security reasons (Blount 1999). ${ }^{18}$ Similarly, as discussed above, independent inventors are delayed more frequently when the patent would naturally take a long time. Conversely, the effect for universities and laboratories drops somewhat in the upper quantiles, although it is still larger than most other categories.

Looking at country trends (the excluded variable is for patents granted to U.S. assignees), we see an interesting pattern. Not surprisingly, for most patents, being from a foreign country slows the application process somewhat, due to translation issues, dual-attorney delays and formatting issues for claims from another system (all noted in the interview section above). However, among patents that naturally take a long time, domestic patents take longer than foreign ones. ${ }^{19}$ Why might this occur? Simply put, patenting in multiple countries is a sign of a valuable patent. Since patent protection is only valid in the country in which a patent is granted, an applicant desiring protection in multiple countries must obtain a patent in each, paying a fee for each. Patent applications are nearly always filed first in the inventor's home country, after which the inventor has one year in which to apply elsewhere. Thus, the applicant only chooses to file abroad if the expected value of the patent justifies the extra expense. Previous work (see, for example, Lanjouw, Pakes, and Putnam 1998) shows that the number of countries in which patent protection is obtained is a good proxy for the value of an invention. Inventions of higher quality are likely to be clearer inventive steps, and thus easier to examine. Questionable patents would be less likely to have broad commercial appeal. Thus, foreign inventors considering applications

\footnotetext{
${ }^{18}$ For example, patent number 4956612 was granted to the U.S. Navy in 1990. The application was filed in 1945, and the other patents cited by this patent were granted during the 1940s. The patent refers to a firing circuit for a mine. Since the granting of a patent requires that the invention be disclosed, it is likely that the government did not want this invention disclosed until its military usefulness had passed.

${ }^{19}$ The one exception is patents from the United Kingdom, which always take longer than domestic patents. The results of U.K. patents suggest that language issues are not the only barriers faced by foreign patent applicants in the U.S.
} 
of patents which tend to have long pendency periods would be less likely to apply for protection in the U.S. as well as their home country.

Turning next to the technology variables, we see that technology differences become more important for patents with errors in the upper quantiles. Compared to the base case of electrical patents, the effect of technology rises in the upper quantiles for every technology except software. $^{20}$ One technology, mechanical patents, experiences a sign change in the upper quantiles. However, the magnitude of the effect of mechanical patents is small (about a 2 percent increase or decrease to the typical grant lag) at both the upper and lower quantiles.

There is a slightly rising effect for citations until the upper quantiles are reached. At that point, adding additional citations doesn't have much effect (because the damage has been done and the $400^{\text {th }}$ citation may not even be read carefully by an examiner). Similarly, the marginal effect of an additional claim falls as we move to the upper quantiles, presumably because there are economies of scale in one examiner evaluating many related claims. However, the marginal effect of a drawing increases in the upper quantiles, suggesting that drawings may add more complexity to the examination process. As with the OLS estimates, however, the magnitudes of these estimates are small, so that the practical effects are near zero.

One reason that the features of a patent have such a small effect is due to the strict time allocation rules used by the USPTO. Adding more claims or more citations adds to the amount of work to be done, but does not change the target number of hours an examiner has to allocate to each patent. Rather, our interviews suggest that the complexity added by additional claims or citations leads to the examiner spending less time on each part of the patent application. Significant increases in time arise when additional communication is needed between the 
examiner and the applicant. Such communications may occur, for example, when a claim is unclear or is too broadly defined, and having more claims may increase the probability of this occurring. However, interviewed examiners said that this need not be the case. A patent may have many claims because each claim is carefully written and defined in a specific, detailed manner. For the examiner, this is more desirable than having a few claims that are too broadly written and are thus open to challenge from the prior art.

Finally, the results for the experience variable are particularly interesting, confirming precisely the responses of patent examiners. Moreover, these results would not be seen without using the quantile technique. Recall that the experience variable was insignificant in the OLS regression. However, that is only the case around the middle of the error distribution. For patents that are likely to get through quickly, having more experience helps to speed the process even further. Conversely, for patents that naturally take a long time to be examined, experience slows the process. Our interviews with patent examiners suggest a possible explanation. Many of the things that can slow an application are simple things that an experienced inventor should be able to avoid. Examples range from simple acts such as not filing the proper paperwork to more complicated tasks such as writing claims in a way that are clear to the examiner. Thus, our expectation beginning this research was that experience would help speed the process. However, experienced applicants may slow the process down by deliberately aiming for broad claims, forming a portfolio with claims of different formats, and acting strategically to eke out every nugget of value from the patenting process. Our results suggest that experience offers some aid to getting through quickly, if that is your goal. However, experience also better enables you to

\footnotetext{
${ }^{20}$ Note that, although the effect of being a software patent is smaller in the upper quantiles, software patents still experience longer delays than most patents. Rather, the grant lag increases by only $20 \%$, rather than $30 \%$ in the lower quantiles.
} 
stay and fight a long, drawn out application. In short, experience helps to get out of purgatory faster or stay there longer, depending on your intentions.

\section{Further Analysis}

Given the large differences across sectors, further exploration of effects within technologies is desirable. One particular interest is to see whether time effects vary by technology. As noted earlier, grant lags have been rising in recent years. Part of this may be due to an overall increase in patent applications. However, the sharp rise in applications for complex technologies is also a factor. An important question is whether the pendency time for these patents has continued to rise as applications rise, or whether the development of the prior art in these fields reduces uncertainty in the patenting process, allowing the grant lag to fall over time.

To check this, we re-ran the OLS regression with an interaction term between the year dummies and dummy variables indicating a patent for each of four technologies: biotechnology, drugs, computers, and software. ${ }^{21}$ Figure 6 plots the time dummies for each of these technologies, as well as the overall time dummy from this regression. ${ }^{22}$ The overall trend controls for year-specific events affecting all patents, such as the budget cuts at USPTO. Note that although the overall trend has been rising over time, it is higher for three of the other four technologies. Drug patents were actually somewhat quicker than other patents during the 80 s, and their year effects did not differ from other technologies in the 90s. However, for the other three technologies, grant lags have been increasing over time more rapidly than for patents as a whole. There is little evidence that experience in these fields has lowered pendency time.

\footnotetext{
${ }^{21}$ These four technologies were chosen because they are the technologies that have experienced the most dramatic growth in recent years.

${ }_{22}$ Other results are similar to the earlier OLS estimation. These results are available from the authors.
} 
Finally, to get a better understanding of the cause of processing delays, we present the results of a logit regression on the probability of a patent having a related application. As noted earlier, a major factor increasing pendency time is the need for communication between the examiner and the applicant. While we do not have a record of each time this occurs, our data include one indicator of such communication. When modifications to the application are required, the applicant is given the choice to abandon the original application and file a new, modified version of the original application. As long as the new application is filed on the same day as the original application is withdrawn, it is labeled a continuation of the original application and given the same priority date as the first application. If the continuation also includes new elements, it is labeled as a "continuation in part." As long as the new claims are substantially related to the original ones, the applicant can keep the original priority date of the patent. Information on related applications is included on the front page of a patent. We use the presence of one or more related applications as an indicator that extra communication between the applicant and the examiner was needed.

Table 6 presents the results of this regression. The last column shows the marginal effects of each independent variable. With the exception of government patents, assignee types have little effect on the probability of having a related application. Foreign applicants are three to nine percent less likely to require a related application. This helps to explain the results in the upper quantiles found for the country dummies - foreign patents are less likely to have applications requiring continuing communication. Once again, technology differences are most important. Biotechnology, chemistry, and organic chemistry patents are more likely to have related applications. Examiners we interviewed say that both the complexity and the pace of technology lead to more related applications. For example, an applicant in biotech may initially 
file very broad claims, but be unable to provide support for each claim. The applicant can then file a continuation for those claims that are supported while continuing to work on the remaining claims. Given these results, we do not anticipate that pendency times will fall over time in these fields. Furthermore, as noted earlier, restrictions (and subsequent divisional applications) are more common in chemical and biotech fields because of the way those technologies need to be claimed. For instance, the patent office places limits on the number of distinct nucleotide sequences that can be claimed in a single patent.

On the other hand, computer and software patents are not more likely to need related applications. Rather, the backlog of existing applications seems to be problematic here. In fact, one examiner in this field noted that the Technology Center was currently working on applications that were over two years old. As a result, increasing the number examiners assigned to these technologies could lower pendency times in these fields, by allowing examiners to work on fewer applications, and thus allowing them to meet the same productivity goals set for other technologies.

\section{Conclusions}

In recent years, both increases in average pendency time and policy changes that are affected by the length of pendency time have led to increased attention of the issue at USPTO. However, little economic research on the subject exists. Both our quantitative research and our interviews with patent examiners suggest that the biggest factor influencing the expected examination time of a patent application is its technological field. Applications in newer, more complex technologies such as biotechnology or computers take significantly longer than other patent applications. Interestingly, there are even differences across these fields. In particular, 
biotechnology patents are more likely to have related applications, suggesting that the complexity of these applications leads to more frequent communications between the examiner and the applicant than in other fields. Since these delays add substantial time to the process (potentially up to eight months for each communication), we do not anticipate that pendency times will fall over time in these fields. On the other hand, computer and software patents are not more likely to need related applications. As a result, increasing the number examiners assigned to these technologies could lower pendency times in these fields, by allowing examiners to work on fewer applications, and thus allowing them to meet the same productivity goals set for other technologies. Furthermore, despite the concerns of independent inventors expressed during debate over the American Inventors Protection Act of 1999, we find little evidence that applications from independent inventors take longer to process than other applications. 


\section{References}

Blount, S., 1999. The use of Delaying Tactics to Obtain Submarine Patents and Amend Around a Patent that a Competitor has Designed Around. Journal of the Patent and Trademark Office Society 81(1), 11-32.

General Accounting Office, 1996. Enhancements Needed In Computing and Reporting Patent Examination Statistics. Report to the Chairman, Committee on the Judiciary (U.S. Senate, Washington, DC).

Hall, B.H., A.B. Jaffe and M. Trajtenberg, 2001. The NBER Patent Citations Data File: Lessons, Insights and Methodological Tools. NBER Working Paper No. 8498.

Johnson, D.K.N. and D. Popp (forthcoming). Forced Out of the Closet: The Impact of the American Inventors Protection Act on the Timing of Patent Disclosure. Rand Journal of Economics, Spring 2003.

King, J.L., 2002. Patent Examination Procedures as Inputs to Patent Quality. unpublished working paper, United States Department of Agriculture Economic Research Service.

Koenker, R. and G. Bassett, 1978. Regression Quantiles. Econometrica 46(1), 33-50.

Koenker, R. and K.F. Hallock, 2001. Quantile Regression. Journal of Economic Perspectives 15(4), 143-156.

Lanjouw, J.O., A. Pakes and J. Putnam, 1998. How to Count Patents and Value Intellectual Property: Uses of Patent Renewal and Application Data. The Journal of Industrial Economics 46(4), 405-433. 
Table 1 - Overall Descriptive Statistics

\begin{tabular}{lcccc}
\hline \hline & Mean & minimum & median & maximum \\
\hline Grant lag (months) & 28.4 & 1 & 23 & 1143 \\
Number of claims & 11.7 & 0 & 9 & 868 \\
Number of sheets & 3.7 & 0 & 2 & 4011 \\
Number of drawings & 7.1 & 0 & 5 & 997 \\
Number of patents cited & 7.2 & 0 & 6 & 454 \\
Number of citations per claim & 1.1 & 0 & 0.6 & 216 \\
Experience & 319.7 & 0 & 25 & 3755 \\
\hline \hline
\end{tabular}


Table 2 - Descriptive Statistics by Assignee

\begin{tabular}{|c|c|c|c|c|c|c|c|c|}
\hline & Firm & Government & Hospitals & Independent & Laboratory & Non-profit & Unassigned & Universities \\
\hline Number & $1,288,213$ & 31,132 & 663 & 17,209 & 2,037 & 1,278 & 294,350 & 18,972 \\
\hline Percent of total & $77.89 \%$ & $1.88 \%$ & $0.04 \%$ & $1.04 \%$ & $0.12 \%$ & $0.08 \%$ & $17.80 \%$ & $1.15 \%$ \\
\hline Grant lag (months) & 28.6 & 31.1 & 40.5 & 28.7 & 35.8 & 30.3 & 26.4 & 37.3 \\
\hline Number of claims & 12.0 & 9.6 & 14.7 & 12.4 & 15.2 & 13.9 & 10.6 & 15.7 \\
\hline Number of sheets & 3.8 & 2.8 & 4.6 & 3.6 & 3.6 & 3.5 & 3.2 & 4.4 \\
\hline Number of drawings & 7.0 & 5.2 & 7.1 & 8.2 & 6.3 & 6.2 & 7.7 & 7.5 \\
\hline Number of patents cited & 7.1 & 5.9 & 6.6 & 8.1 & 7.1 & 8.0 & 7.8 & 6.8 \\
\hline Number of citations per claim & 1.0 & 1.1 & 0.7 & 1.2 & 0.8 & 0.9 & 1.4 & 0.7 \\
\hline Experience & 397.5 & 487.4 & 14.9 & 0.0 & 32.1 & 63.8 & 0.0 & 73.0 \\
\hline
\end{tabular}

Table 3 - Descriptive Statistics by Technology

\begin{tabular}{|c|c|c|c|c|c|c|c|c|c|c|}
\hline & Biotech & Chemicals & Computers & Drugs & Electrical & Mechanical & Medical & Misc. & $\begin{array}{c}\text { Org. } \\
\text { Chem. }\end{array}$ & Software \\
\hline Number & 17,009 & 283,102 & 114,574 & 55,961 & 282,972 & 375,533 & 55,349 & 355,878 & 62,843 & 50,633 \\
\hline Percent of total & $1 \%$ & $17 \%$ & $7 \%$ & $3 \%$ & $17 \%$ & $23 \%$ & $3 \%$ & $22 \%$ & $4 \%$ & $3 \%$ \\
\hline Grant lag (months) & 44.6 & 30.2 & 30.7 & 37.8 & 26.5 & 26.3 & 29.8 & 25.2 & 34.7 & 35.4 \\
\hline Number of claims & 13.1 & 12.4 & 12.7 & 12.9 & 11.9 & 10.9 & 13.5 & 11.1 & 10.0 & 13.9 \\
\hline Number of sheets & 3.9 & 1.9 & 6.3 & 0.9 & 4.4 & 4.1 & 3.9 & 3.3 & 0.5 & 8.9 \\
\hline Number of drawings & 5.2 & 3.6 & 10.6 & 1.2 & 8.6 & 8.2 & 9.3 & 7.4 & 0.7 & 12.8 \\
\hline Number of patents cited & 4.2 & 7.4 & 6.7 & 4.7 & 6.4 & 7.3 & 10.1 & 8.3 & 4.0 & 8.3 \\
\hline Number of citations per claim & 0.6 & 1.0 & 0.9 & 0.6 & 0.9 & 1.2 & 1.3 & 1.3 & 0.8 & 1.1 \\
\hline Experience & 136.8 & 344.0 & 687.5 & 187.5 & 520.0 & 239.1 & 89.7 & 107.7 & 362.5 & 725.7 \\
\hline
\end{tabular}


Table 4 - Descriptive Statistics by Country

\begin{tabular}{|c|c|c|c|c|c|c|c|c|}
\hline & U.S. & Japan & Germany & France & U.K. & Canada & Other EPO & Other \\
\hline Number & 929,977 & 298,752 & 137,382 & 52,117 & 52,068 & 29,635 & 102,892 & 51,031 \\
\hline Percent of total & $56 \%$ & $18 \%$ & $8 \%$ & $3 \%$ & $3 \%$ & $2 \%$ & $6 \%$ & $3 \%$ \\
\hline Grant lag (months) & 28.8 & 28.1 & 26.8 & 28.2 & 30.2 & 26.5 & 28.4 & 25.8 \\
\hline Number of claims & 12.8 & 10.1 & 10.9 & 10.7 & 11.1 & 12.2 & 10.3 & 9.1 \\
\hline Number of sheets & 3.4 & 5.8 & 2.3 & 2.8 & 2.8 & 3.7 & 2.5 & 3.7 \\
\hline Number of drawings & 6.9 & 10.5 & 4.2 & 5.6 & 5.1 & 7.0 & 5.1 & 6.7 \\
\hline Number of patents cited & 8.4 & 5.4 & 5.4 & 5.5 & 5.9 & 7.9 & 5.7 & 6.0 \\
\hline Number of citations per claim & 1.2 & 1.0 & 0.8 & 0.8 & 0.9 & 1.1 & 0.9 & 1.3 \\
\hline Experience & 276.6 & 635.6 & 319.3 & 111.9 & 153.7 & 61.9 & 180.3 & 69.3 \\
\hline \multicolumn{9}{|l|}{ Percentage by assignee } \\
\hline Firm & $71 \%$ & $96 \%$ & $90 \%$ & $82 \%$ & $87 \%$ & $60 \%$ & $84 \%$ & $56 \%$ \\
\hline Government & $3 \%$ & $0 \%$ & $0 \%$ & $7 \%$ & $3 \%$ & $2 \%$ & $0 \%$ & $1 \%$ \\
\hline Hospital & $0 \%$ & $0 \%$ & $0 \%$ & $0 \%$ & $0 \%$ & $0 \%$ & $0 \%$ & $0 \%$ \\
\hline Individual & $1 \%$ & $0 \%$ & $1 \%$ & $1 \%$ & $1 \%$ & $1 \%$ & $1 \%$ & $2 \%$ \\
\hline Laboratory & $0 \%$ & $0 \%$ & $0 \%$ & $0 \%$ & $0 \%$ & $0 \%$ & $0 \%$ & $0 \%$ \\
\hline Non-Profit & $0 \%$ & $0 \%$ & $0 \%$ & $0 \%$ & $0 \%$ & $0 \%$ & $0 \%$ & $0 \%$ \\
\hline Unassigned & $23 \%$ & $3 \%$ & $9 \%$ & $11 \%$ & $10 \%$ & $36 \%$ & $15 \%$ & $41 \%$ \\
\hline University & $2 \%$ & $0 \%$ & $0 \%$ & $0 \%$ & $0 \%$ & $0 \%$ & $0 \%$ & $0 \%$ \\
\hline \multicolumn{9}{|l|}{ Percentage by technology } \\
\hline Biotechnology & $1 \%$ & $1 \%$ & $1 \%$ & $1 \%$ & $1 \%$ & $1 \%$ & $1 \%$ & $1 \%$ \\
\hline Chemicals & $17 \%$ & $17 \%$ & $21 \%$ & $17 \%$ & $17 \%$ & $16 \%$ & $18 \%$ & $14 \%$ \\
\hline Computers & $6 \%$ & $12 \%$ & $3 \%$ & $7 \%$ & $6 \%$ & $6 \%$ & $4 \%$ & $5 \%$ \\
\hline Drugs & $3 \%$ & $2 \%$ & $4 \%$ & $6 \%$ & $8 \%$ & $3 \%$ & $5 \%$ & $4 \%$ \\
\hline Electrical & $16 \%$ & $22 \%$ & $15 \%$ & $19 \%$ & $17 \%$ & $13 \%$ & $14 \%$ & $18 \%$ \\
\hline Mechanical & $21 \%$ & $26 \%$ & $27 \%$ & $22 \%$ & $22 \%$ & $24 \%$ & $24 \%$ & $23 \%$ \\
\hline Medical & $4 \%$ & $1 \%$ & $2 \%$ & $2 \%$ & $2 \%$ & $3 \%$ & $3 \%$ & $4 \%$ \\
\hline Miscellaneous & $25 \%$ & $12 \%$ & $18 \%$ & $18 \%$ & $19 \%$ & $32 \%$ & $23 \%$ & $27 \%$ \\
\hline Organic Chemistry & $3 \%$ & $3 \%$ & $7 \%$ & $5 \%$ & $5 \%$ & $2 \%$ & $6 \%$ & $3 \%$ \\
\hline Software & $3 \%$ & $5 \%$ & $1 \%$ & $3 \%$ & $2 \%$ & $2 \%$ & $1 \%$ & $2 \%$ \\
\hline
\end{tabular}


Table 5 - OLS Results

\begin{tabular}{|c|c|c|c|c|c|}
\hline & Estimate & T-stat & $\exp (\beta)-1$ & mean effect & $\begin{array}{c}\text { median } \\
\text { effect }\end{array}$ \\
\hline Intercept & 2.99407 & 1325.65 & $19.97^{*}$ & & \\
\hline Unassigned & -0.03509 & -33 & -0.03 & & \\
\hline Individual & 0.02357 & 6.42 & 0.02 & & \\
\hline Government & -0.01578 & -5.72 & -0.02 & & \\
\hline University & 0.16228 & 45.8 & 0.18 & & \\
\hline Hospital & 0.20177 & 10.9 & 0.22 & & \\
\hline Laboratory & 0.14257 & 13.49 & 0.15 & & \\
\hline Non-profit & 0.05632 & 4.22 & 0.06 & & \\
\hline Japan & 0.02729 & 24.99 & 0.03 & & \\
\hline Germany & 0.00857 & 6.09 & 0.01 & & \\
\hline France & 0.04066 & 18.79 & 0.04 & & \\
\hline United Kingdom & 0.08852 & 40.98 & 0.09 & & \\
\hline Canada & -0.02459 & -8.73 & -0.02 & & \\
\hline Other EPO & 0.0523 & 33.01 & 0.05 & & \\
\hline Other Country & -0.02495 & -11.4 & -0.02 & & \\
\hline Chemicals & 0.10726 & 83.02 & 0.11 & & \\
\hline Organic Chemistry & 0.26069 & 121.78 & 0.30 & & \\
\hline Computers & 0.1258 & 75.07 & 0.13 & & \\
\hline Software & 0.26074 & 112.38 & 0.30 & & \\
\hline Biotechnology & 0.52534 & 138.33 & 0.69 & & \\
\hline Medical & 0.08423 & 37.39 & 0.09 & & \\
\hline Drugs & 0.35688 & 158.89 & 0.43 & & \\
\hline Mechanical & -0.01743 & -14.45 & -0.02 & & \\
\hline Miscellaneous & -0.06458 & -51.55 & -0.06 & & \\
\hline issue year 1977 & -0.046 & -17.77 & -0.04 & & \\
\hline issue year 1978 & -0.04204 & -16.28 & -0.04 & & \\
\hline issue year 1979 & 0.00176 & 0.63 & 0.00 & & \\
\hline issue year 1980 & 0.10135 & 38.53 & 0.11 & & \\
\hline issue year 1981 & 0.08881 & 34.29 & 0.09 & & \\
\hline issue year 1982 & 0.13197 & 49.18 & 0.14 & & \\
\hline issue year 1983 & 0.1751 & 64.78 & 0.19 & & \\
\hline issue year 1984 & 0.1609 & 62.02 & 0.17 & & \\
\hline issue year 1985 & 0.11417 & 44.56 & 0.12 & & \\
\hline issue year 1986 & 0.07077 & 27.42 & 0.07 & & \\
\hline issue year 1987 & 0.02316 & 9.25 & 0.02 & & \\
\hline issue year 1988 & -0.01792 & -7.02 & -0.02 & & \\
\hline issue year 1989 & -0.05226 & -21.17 & -0.05 & & \\
\hline issue year 1990 & -0.08035 & -31.9 & -0.08 & & \\
\hline issue year 1991 & -0.06092 & -24.23 & -0.06 & & \\
\hline issue year 1992 & -0.04021 & -15.81 & -0.04 & & \\
\hline issue year 1993 & -0.01738 & -6.74 & -0.02 & & \\
\hline issue year 1994 & -0.00298 & -1.14 & 0.00 & & \\
\hline issue year 1995 & 0.01865 & 6.98 & 0.02 & & \\
\hline issue year 1996 & 0.08285 & 30.56 & 0.09 & & \\
\hline
\end{tabular}

Table continued on next page 
Table 5 - OLS Results (continued)

\begin{tabular}{lccccc} 
& Estimate & T-stat & $\exp (\beta)-1$ & mean effect & $\begin{array}{c}\text { median } \\
\text { effect }\end{array}$ \\
\hline Experience & -0.00000114 & -1.71 & $-1.14 \mathrm{E}-06$ & $-3.64 \mathrm{E}-04$ & $-2.85 \mathrm{E}-05$ \\
Issue year * cites & -0.00044104 & -39.96 & $-4.41 \mathrm{E}-04$ & -0.21 & -0.18 \\
\# of Citations & 0.05023 & 49.86 & 0.05 & 0.44 & 0.35 \\
\# of Claims & 0.00066735 & 17.08 & $6.68 \mathrm{E}-04$ & 0.01 & 0.01 \\
\# of Drawings & 0.00632 & 103.28 & 0.01 & 0.05 & 0.03 \\
\# of Sheets & -0.00005925 & -0.67 & $-5.92 \mathrm{E}-05$ & $-2.16 \mathrm{E}-04$ & $-1.18 \mathrm{E}-04$ \\
\hline \hline
\end{tabular}

* -- For the intercept, we report $e(\beta)$. This value is the expected grant lag for a "base patent," which is assigned to a U.S. firm, was issued in 1976, in the electrical sector, has no experience, and no citations, claims, drawings, or sheets.

Number of observations:

1653854

Adjusted R-square

0.1047 
Table 6 - Probability of a Related Application - Logit Results

\begin{tabular}{|c|c|c|c|c|}
\hline Variable & Estimate & $\begin{array}{r}\text { Standard } \\
\text { Error }\end{array}$ & $\begin{array}{r}\text { Chi- } \\
\text { Square }\end{array}$ & $\begin{array}{l}\text { marg } \\
\text { effect }\end{array}$ \\
\hline Intercept & -1.726 & 0.012 & 21480.307 & -0.281 \\
\hline Unassigned & -0.193 & 0.006 & 1139.541 & -0.032 \\
\hline Individual & -0.004 & 0.019 & 0.051 & -0.001 \\
\hline Government & -0.719 & 0.018 & 1682.429 & -0.117 \\
\hline University & 0.159 & 0.016 & 96.583 & 0.026 \\
\hline Hospital & 0.082 & 0.083 & 0.967 & 0.013 \\
\hline Laboratory & 0.166 & 0.049 & 11.405 & 0.027 \\
\hline Non-profit & -0.077 & 0.067 & 1.328 & -0.013 \\
\hline Japan & -0.339 & 0.006 & 3448.931 & -0.055 \\
\hline Germany & -0.566 & 0.008 & 4901.995 & -0.092 \\
\hline France & -0.469 & 0.012 & 1430.170 & -0.076 \\
\hline United Kingdom & -0.177 & 0.011 & 243.942 & -0.029 \\
\hline Canada & -0.208 & 0.015 & 190.003 & -0.034 \\
\hline Other EPO & -0.308 & 0.009 & 1304.882 & -0.050 \\
\hline Other Country & -0.467 & 0.013 & 1369.625 & -0.076 \\
\hline Chemicals & 0.890 & 0.007 & 17316.304 & 0.145 \\
\hline Organic Chemistry & 1.471 & 0.010 & 21464.050 & 0.240 \\
\hline Computers & -0.005 & 0.009 & 0.328 & -0.001 \\
\hline Software & 0.105 & 0.012 & 71.895 & 0.017 \\
\hline Biotechnology & 1.394 & 0.017 & 6759.936 & 0.227 \\
\hline Medical & 0.395 & 0.011 & 1190.749 & 0.064 \\
\hline Drugs & 1.617 & 0.010 & 24213.820 & 0.263 \\
\hline Mechanical & 0.169 & 0.007 & 626.358 & 0.027 \\
\hline Miscellaneous & 0.097 & 0.007 & 190.297 & 0.016 \\
\hline issue year 1977 & -0.078 & 0.013 & 34.318 & -0.013 \\
\hline issue year 1978 & -0.110 & 0.013 & 66.939 & -0.018 \\
\hline issue year 1979 & -0.127 & 0.015 & 75.536 & -0.021 \\
\hline issue year 1980 & -0.209 & 0.014 & 227.244 & -0.034 \\
\hline issue year 1981 & -0.255 & 0.014 & 345.150 & -0.041 \\
\hline issue year 1982 & -0.241 & 0.014 & 287.886 & -0.039 \\
\hline issue year 1983 & -0.263 & 0.014 & 333.716 & -0.043 \\
\hline issue year 1984 & -0.305 & 0.014 & 484.752 & -0.050 \\
\hline issue year 1985 & -0.341 & 0.014 & 616.852 & -0.056 \\
\hline issue year 1986 & -0.340 & 0.014 & 601.105 & -0.055 \\
\hline issue year 1987 & -0.235 & 0.013 & 315.655 & -0.038 \\
\hline issue year 1988 & -0.149 & 0.013 & 125.728 & -0.024 \\
\hline issue year 1989 & -0.099 & 0.013 & 60.628 & -0.016 \\
\hline issue year 1990 & -0.049 & 0.013 & 14.215 & -0.008 \\
\hline issue year 1991 & -0.079 & 0.013 & 36.694 & -0.013 \\
\hline issue year 1992 & -0.006 & 0.013 & 0.190 & -0.001 \\
\hline issue year 1993 & 0.016 & 0.013 & 1.475 & 0.003 \\
\hline issue year 1994 & 0.040 & 0.013 & 9.002 & 0.007 \\
\hline issue year 1995 & 0.127 & 0.014 & 86.953 & 0.021 \\
\hline issue year 1996 & 0.206 & 0.014 & 224.047 & 0.033 \\
\hline
\end{tabular}

Table continued on next page 
Table 6 - Probability of a Related Application - Logit Results (continued)

\begin{tabular}{lrrrr} 
Variable & Estimate & $\begin{array}{r}\text { Standard } \\
\text { Error }\end{array}$ & $\begin{array}{r}\text { Chi- } \\
\text { Square }\end{array}$ & $\begin{array}{r}\text { marg } \\
\text { effect }\end{array}$ \\
\hline Experience & 0.000 & 0.000 & 445.960 & 0.000 \\
\hline Issue year * & & & & \\
cites & 0.000 & 0.000 & 0.818 & 0.000 \\
\# of Citations & 0.027 & 0.005 & 27.346 & 0.004 \\
\# of Claims & -0.005 & 0.000 & 736.044 & -0.001 \\
\# of Drawings & 0.029 & 0.000 & 4910.565 & 0.005 \\
\# of Sheets & -0.007 & 0.001 & 95.401 & -0.001 \\
\hline \hline
\end{tabular}




\section{Figure 1 - Distribution of Grant Lags}

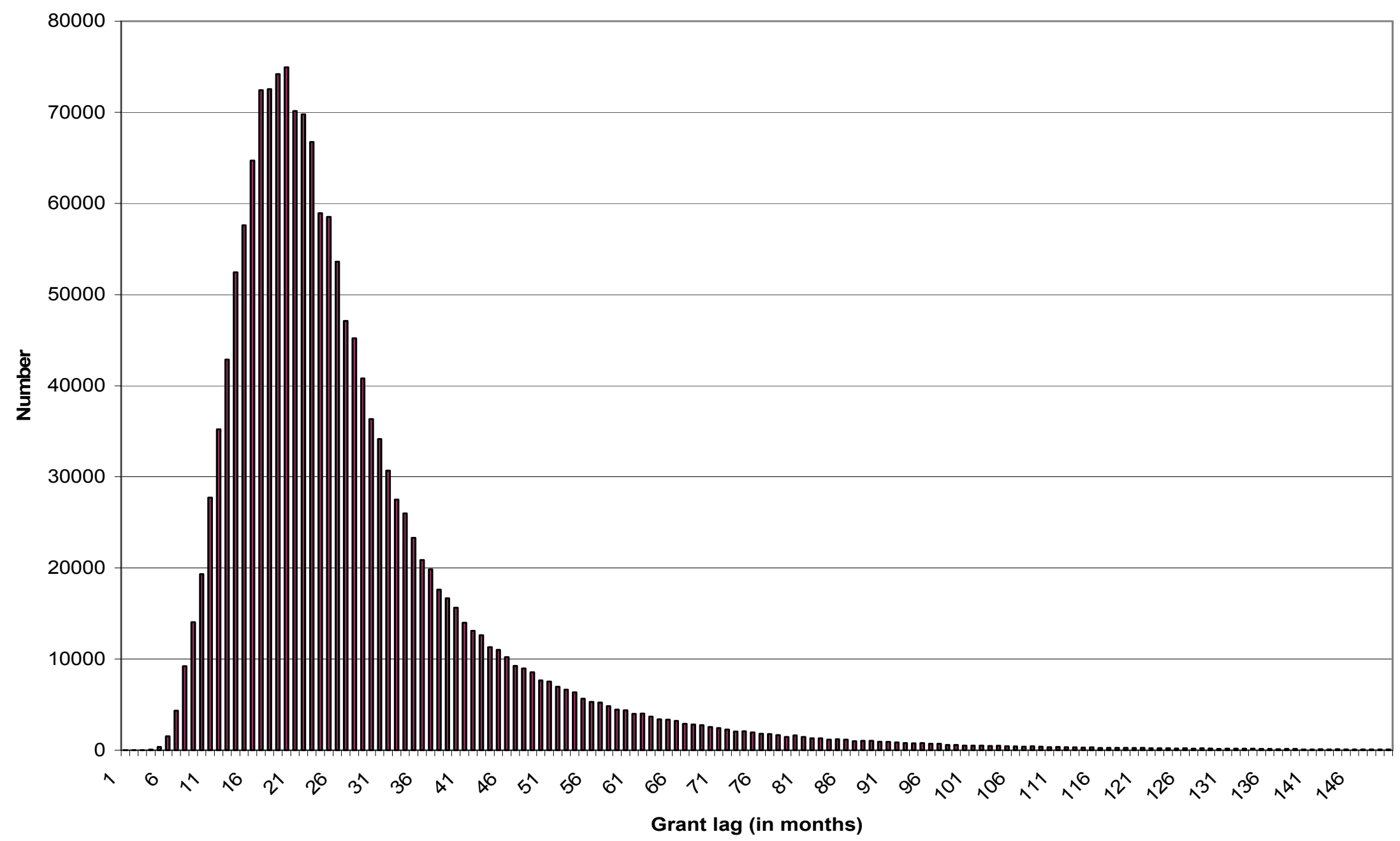




\section{Figure 2 - Number of Patents by Assignee Type}

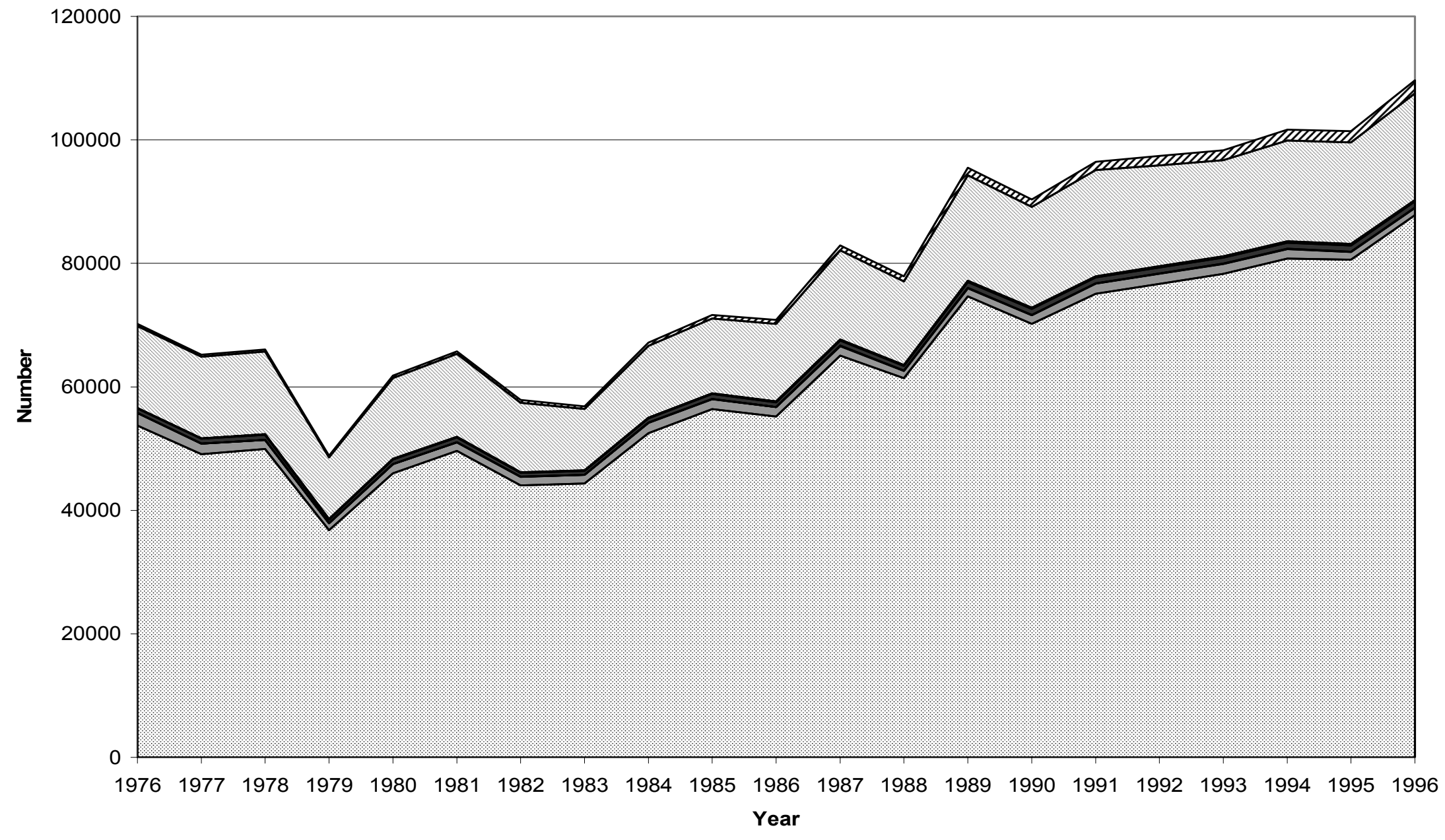

曾 firm $\square$ gov 田hospital $\square$ independent $\square$ lab $\square$ nonprofit $\square$ unassigned $\square$ univ 


\section{Figure 3 - Number of Patents by Technology}

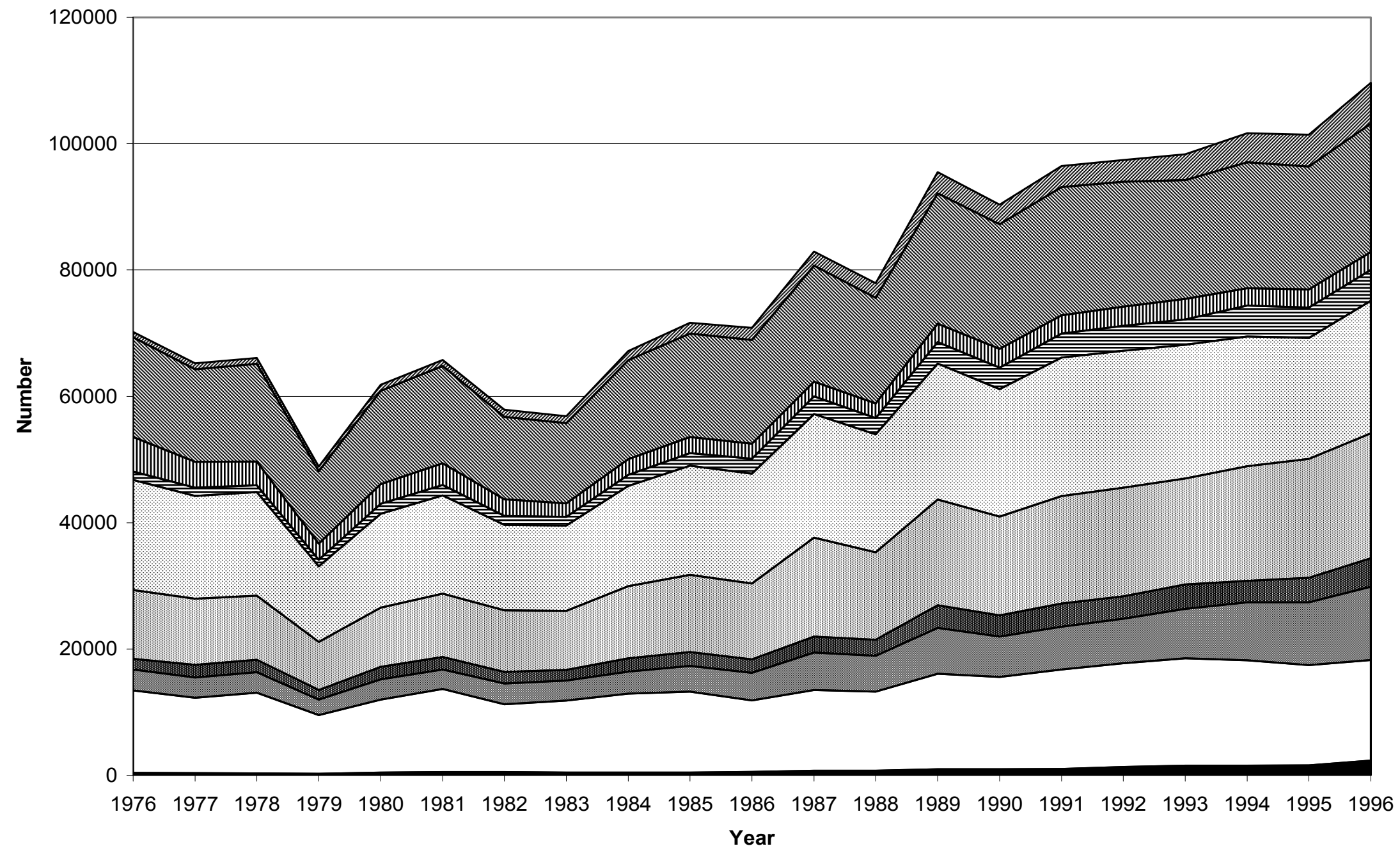

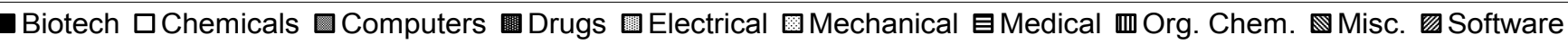




\section{Figure 4 - Mean Grant Lag by Year}

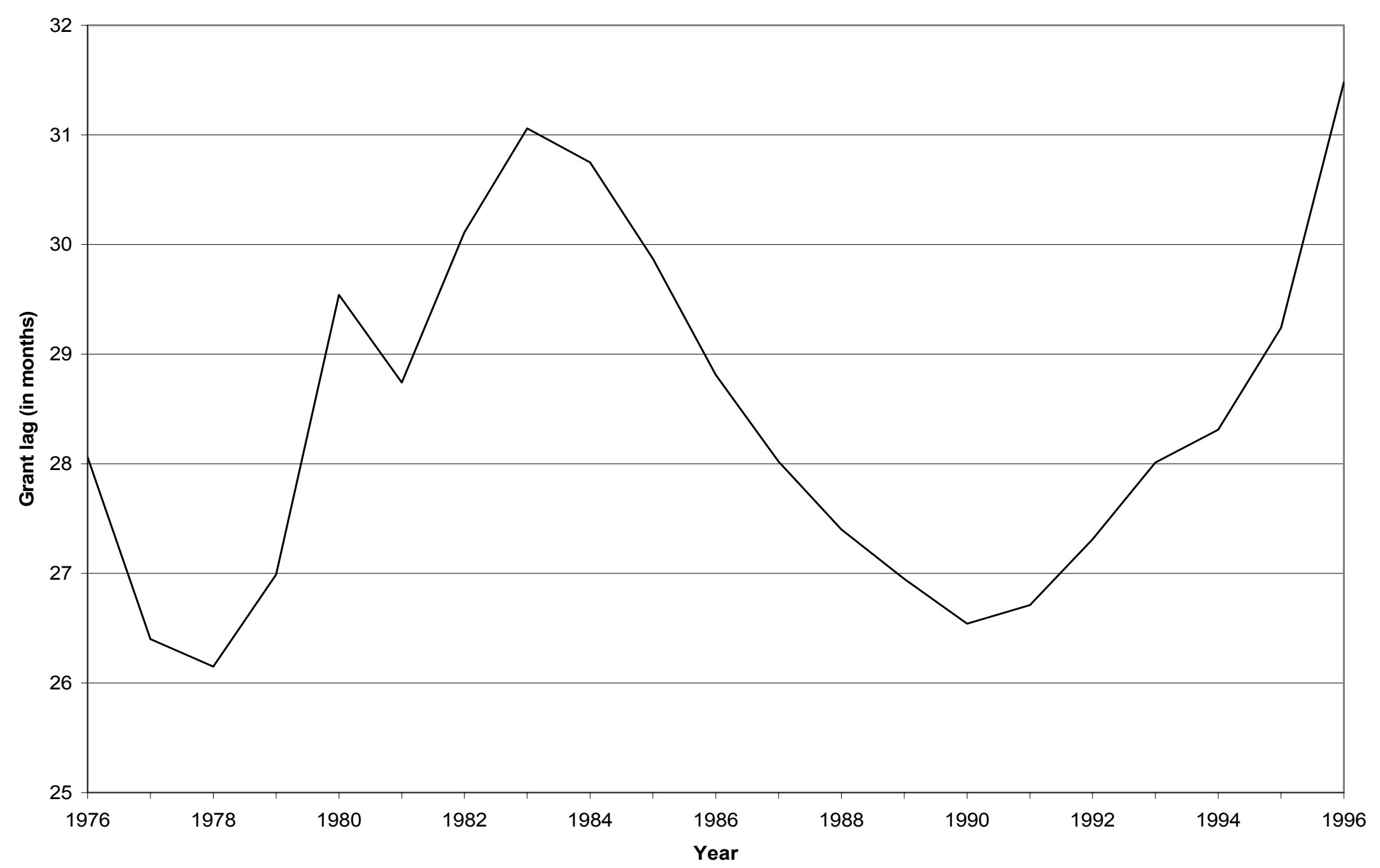

The figure shows the mean grant lag for patents granted in a given year. 
Figure 5 -- Quantile Regression Results
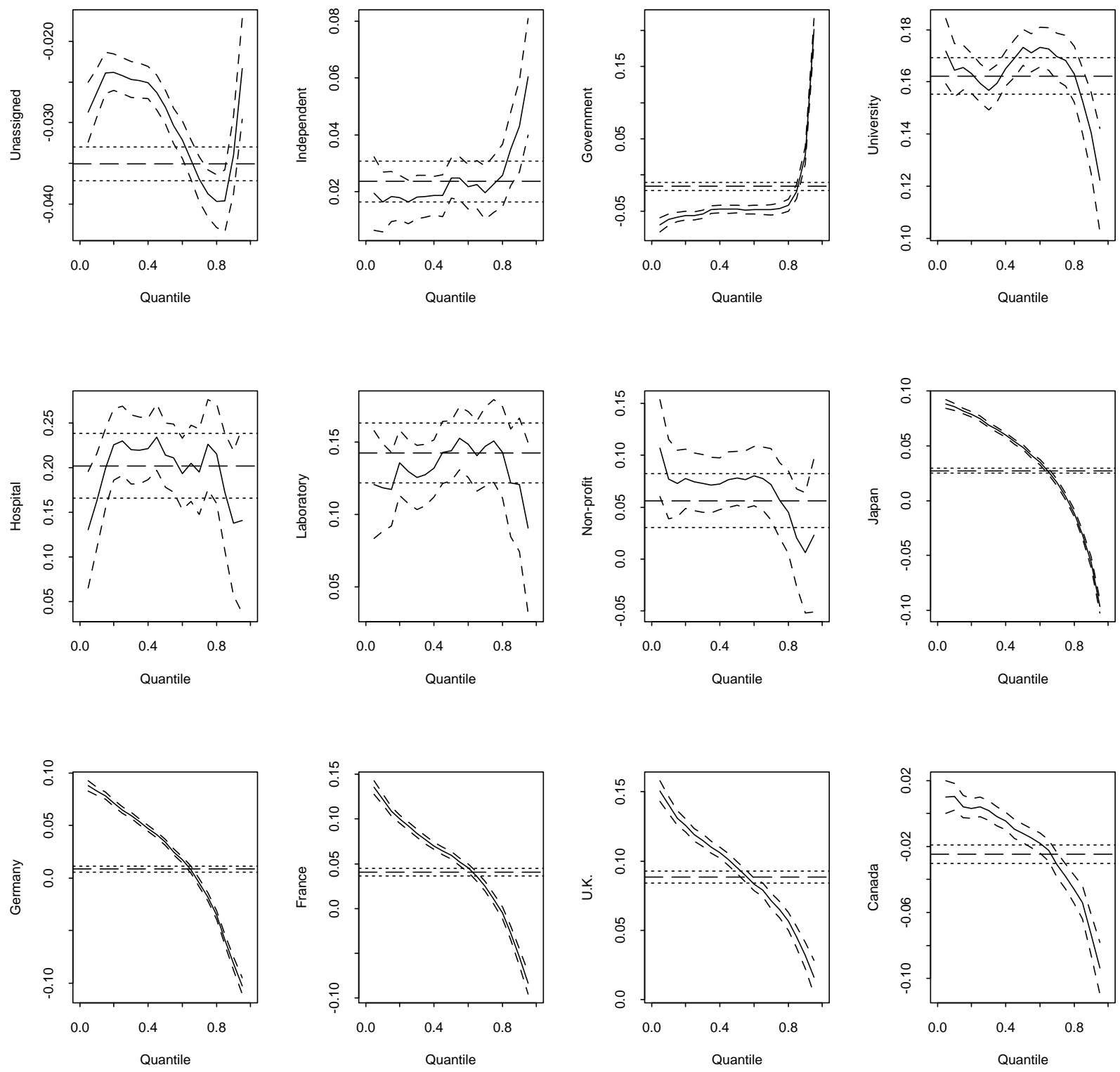
Figure 5 -- Quantile Regression Results (continued)
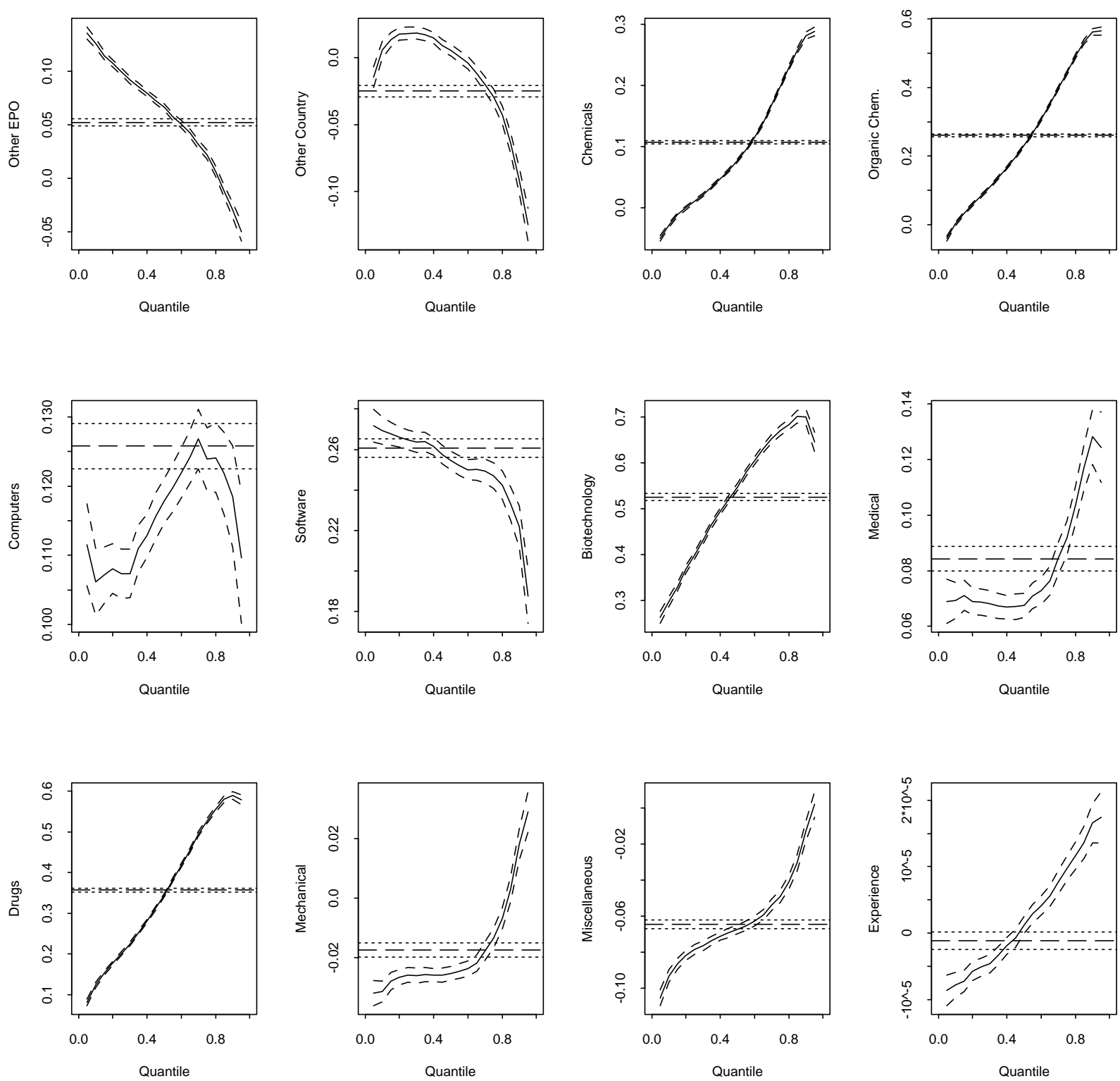
Figure 5 -- Quantile Regression Results (continued)
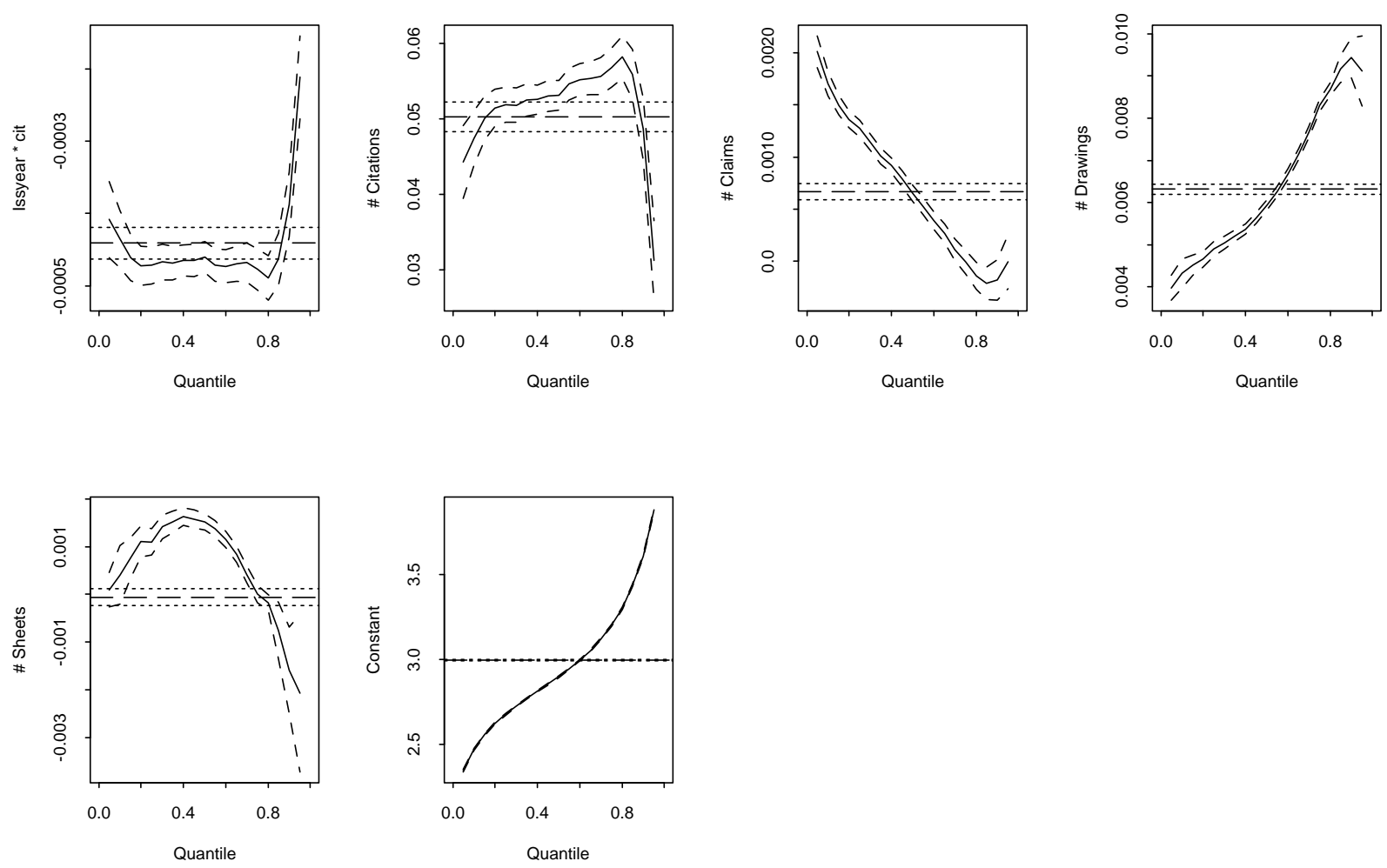


\section{Table 6 - Time Effects by Technology Sector}

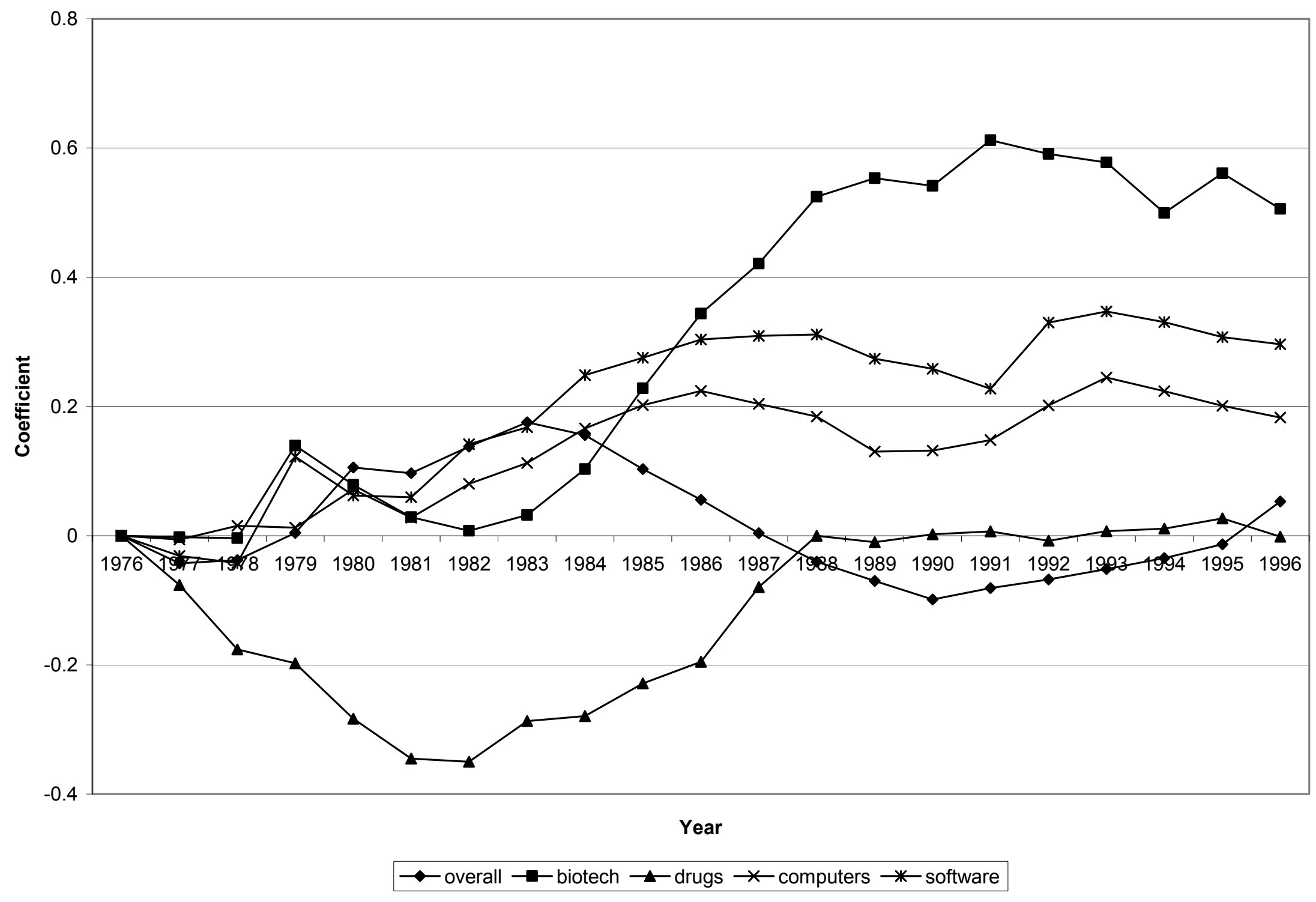

